\title{
PEA/UNESCO BRASIL: A EXPERIÊNCIA DA PRIMEIRA ESCOLA ASSOCIADA DE SANTA MARIA/RS
}

http://dx.doi.org/10.5902/2318133829924

\author{
Gilsilene Rony Pereira Alves \\ Sabrina Magrini Peixoto Machado \\ Escola Municipal de Educação Infantil Borges de Medeiros, Brasil.
}

\begin{abstract}
Resumo
Neste texto descreve-se a experiência de participação da Escola Municipal de Educação Infantil Borges de Medeiros, de Santa Maria/RS, no Programa Escolas Associadas da Unesco PEA/Unesco. Este programa tem como objetivo disseminar os valores da Unesco no âmbito da comunidade escolar, com vistas a fazer de cada escola uma célula da organização e que busque formar líderes capazes de transformar e melhorar a vida na sua comunidade. A Emei Borges de Medeiros participou da edição do PEA/Unesco de 2017 e foi certificada pelo desenvolvimento do projeto intitulado Com imaginação $e$ ação as crianças transformam em realidade a sustentabilidade, que envolveu atividades relacionadas com valores para a boa convivência, respeito ao próximo, alimentação saudável, conhecimento de fauna e flora, dos répteis, cuidado com a saúde do corpo, valorização da cultura local com apresentações artísticas e educação musical.

Palavras-chave: educação infantil; Programa Escolas Associadas da Unesco; Emei Borges de Medeiros.
\end{abstract}

\section{PEA/UNESCO BRAZIL: THE EXPERIENCE OF THE FIRST ASSOCIATED SCHOOL IN SANTA MARIA/RS}

\begin{abstract}
This paper describes the experience of participating in the Program of Unesco Associated Schools - PEA - by Escola Municipal de Educação Infantil Borges de Medeiros from Santa Maria in the state of Rio Grande do Sul. The program aims to spread Unesco's values in the school community viewing to make, out of each school an organization cell and also to form leadership able to change and to improve life in communities. Emei Borges de Medeiros has participated in PEA/Unesco and has been certified for developing the project called Through imagination and action children transform sustainability into reality. Activities related to values for good taking along, respect to the other, healthy eating habits, knowledge of fauna and flora, reptiles, care to body health, valorization of social culture, artistic performances and musical education were developed. Key-words: children education; Unesco Associated School Program; Emei Borges de Medeiros.
\end{abstract}




\section{Introdução}

escola de educação infantil tem buscado o reconhecimento da sociedade
como um nível educacional com suas especificidades. Seus profissionais
buscam a valorização da categoria por melhores condições de trabalho, remuneração adequada e políticas públicas que favoreçam a ampliação deste nível de ensino. Esta demanda recebe o apoio de diversos segmentos da sociedade, principalmente dos movimentos sociais e organizações não governamentais, mas o apoio dos instituições internacionais tem se tornado, nas últimas décadas, um fator essencial na elaboração de políticas públicas para a educação em todos os níveis e modalidades.

Um dos principais instituições internacionais que atua a mais de quatro décadas no Brasil e existe a mais de sessenta anos no mundo é a Organização das Nações Unidas para a Educação, a Ciência e a Cultura - Unesco. Esta organização surgiu em 1945 após a Segunda Guerra Mundial com o objetivo de garantir a paz mundial a partir da colaboração intelectual dos países, buscando soluções adequadas e sustentáveis para os problemas sociais. No Brasil a Unesco está presente desde 1964, com escritório em Brasília desde 1972, e sua atuação busca a qualidade da educação e o desenvolvimento humano e social. A Unesco atua nas áreas de educação, ciências humanas e sociais, ciências naturais, cultura, comunicação e informação, realizando um trabalho conjunto apoiando-se nas novas tecnologias para desenvolver projetos de formação de professores e facilitar o acesso as informações. Para atender, especificamente, a educação, criou-se o Programa Escolas Associadas da Unesco - PEA/Unesco. Com o objetivo de criar uma rede de escolas associadas que trabalhem os quatro eixos propostos: a educação do desenvolvimento sustentável, o aprendizado intercultural, os problemas mundiais e o papel do sistema das Nações Unidas e a paz e os direitos do homem.

O Programa de Escolas Associadas tem a intenção de expandir sua atuação buscando o apoio das secretarias de educação para apresentar a proposta para as escolas das diferentes redes de ensino do Brasil. As escolas da região central de Santa Maria/RS tiveram a oportunidade de conhecer o PEA em uma das reuniões realizadas pela Secretaria de Educação de Santa Maria no ano de 2016, quando a relatora do Programa das Escolas Associadas, Sueli Schabbach Matos da Silva, mostrou aos coordenadores e diretores de escolas quais os objetivos do programa e quais os passos a serem seguidos. Nesta formação foi dado o primeiro passo para as escolas interessadas buscarem a certificação.

Este artigo tem por objetivo apresentar a experiência da Escola Municipal de Educação Infantil Borges de Medeiros, a primeira escola do Centro do Estado do Rio Grande do Sul a se associar ao Programa Escolas Associadas da Unesco. Apresentamos um relato dos projetos realizados na escola e os caminhos seguidos até chegar a esta certificação que, para as escolas de educação infantil, representa o reconhecimento e valorização do trabalho dos professores e um apoio na busca pela qualidade do ensino da rede pública. 


\section{Por uma educação infantil de qualidade}

O direito a uma educação infantil de qualidade e acessível a todos é uma busca constante da nossa sociedade. Em 1940 surgiu o Departamento Nacional da Criança, vinculado ao Ministério da Saúde e destinado a coordenar as atividades nacionais relativas à proteção da infância, da maternidade e da adolescência. Em 1946 foi criada a Legião Brasileira de Assistência - LBA -, que passou a ser a entidade destinada a executar as políticas sociais para a família, a maternidade e a infância. Segundo Campos; Rosemberg; Ferreira (1993), "a LBA foi criada em 1942, tendo como objetivo inicial amparar os convocados para a II Guerra Mundial e suas famílias. Porém, desde sua criação, suas metas previam sua fixação como instituição destinada a desenvolver serviços de assistência social" (p. 30).

A partir da década de 1950, as creches existentes fora das indústrias, na sua maioria, eram de responsabilidade de entidades filantrópicas e muitas delas de cunho religioso, cujo objetivo era suprir as carências da pobreza. Segundo Kuhlmann Jr. (2001),

a pequena oferta de atendimento supunha o estabelecimento de um clima de competição entre os que necessitassem dos serviços: os mais subservientes seriam atendidos. Além disso, o caráter de baixa qualidade dos serviços prestados era um meio para não torná-lo atraente e alvo de reivindicações generalizadas. Quem quisesse o atendimento precisaria expor sua vida privada ao escrutínio dos que ofereciam. (p. 67)

As primeiras preocupações destas instituições eram com a alimentação, os cuidados da higiene e a segurança física, sendo pouco valorizado o trabalho de desenvolvimento intelectual e afetivo com as crianças. Durante os anos 1950 destaca-se a criação de algumas importantes instituições, como a Legião Brasileira de Assistência, o Fundo das Nações Unidas pela Infância e a Organização Mundial de Educação PréEscolar.

Nos anos de 1960 mudou a política voltada para a infância e em 1964 foi criada a Fundação Nacional de Bem-Estar do Menor. Segundo análise de Campos (1993) havia a preocupação em propor uma reforma no atendimento do menor abandonado. Teve então início uma proposta de educação compensatória, sendo as crianças de classe pobre, privadas culturalmente, o alvo, pois tal privação justificava o fracasso dessas na escola.

Durante a década de 1960 a Unicef e outras agências ligadas à ONU, como a Unesco, ampliavam sua atuação em relação à infância e reconheciam a importância desta etapa do desenvolvimento para a formação de cidadãos preocupados com o bemestar social e com o desenvolvimento econômico responsável das nações.

Nos anos de 1970 foi criado o Conselho Federal de Educação e em 1974 o Projeto Casulo, vinculado à Legião Brasileira de Assistência, que se expandiu e passou a atuar de maneira sistemática na área de creche. Neste foi criada a Coordenação de Educação Pré-Escolar, vinculada ao Ministério da Educação e da Cultura. Após 1970, com o objetivo de assistir os filhos das mães trabalhadoras, a ênfase no cuidado das crianças pequenas fez com que se disseminassem inúmeras instituições de Educação Infantil pelo país. 
No início da década de 1980 a educação pré-escolar foi instituída oficialmente, entendida como política governamental pelo III Plano Setorial de Educação, Cultura e Desporto. Neste período surgiram inúmeras dúvidas sobre a função compensatória da pré-escola e começou-se a pensar uma nova identidade para as creches, considerando o direito da criança e da mãe a um atendimento de qualidade.

Com a Constituição Federal de 1988 foi garantido o direito das crianças de 0 a 6 anos de frequentarem creches e pré-escolas. O artigo 208, inciso IV, afirma que "o dever do Estado com a educação será efetivado mediante a garantia de [...] atendimento em creche e pré-escola às crianças de zero a cinco anos de idade" (CF, 1988).

Com a Lei de Diretrizes e Bases da Educação de 1996 mudou-se o sentido de educação infantil, que passou a ser responsabilidade dos municípios, uma etapa da educação básica, e a requerer profissionais com formação específica em nível médio magistério ou curso superior em Pedagogia.

\section{O Programa Escolas Associadas da Unesco}

A Unesco foi criada em 16 de novembro de 1945 como uma extensão da Organização das Nações Unidas - ONU. O Programa Escolas Associadas da Unesco com sede em Paris, existe desde 1953 e estende os valores da ONU para o âmbito educacional e está presente em 181 países.

No Brasil o PEA atua intensamente desde 1997, com a coordenação nacional sediada no Rio de Janeiro. O PEA tem como objetivo criar uma rede internacional de escolas que trabalhem a cultura da paz. As escolas associadas têm como tarefa trabalhar o ano internacional proposto pela instituição, tema central, e ampliar a consciência de cidadania. No Brasil, O PEA já certificou 364 escolas, sendo a segunda maior rede do mundo. Destas 364 escolas associadas, 77 receberam a notícia da certificação em março de 2017. O certificado foi entregue em um congresso realizado em Foz do Iguaçu em setembro deste mesmo ano.

Para valorizar e incentivar a qualidade da educação básica o PEA busca contribuir para a efetivação dos objetivos da agenda 2030. Na 70a Sessão da Assembléia Geral das Nações Unidas foi adotada uma agenda de desenvolvimento global, intitulada Transformar nosso mundo: agenda 2030 para o desenvolvimento sustentável. Esta agenda norteia o trabalho a nível educacional, definindo 17 objetivos de desenvolvimento sustentável. A Unesco reconhece a educação como ferramenta de superação dos problemas sociais e ambientais e aposta todas suas fichas na elaboração e execução de metas que combatem a pobreza, os problemas ambientais, as desigualdades de acesso a educação, objetivando uma educação de qualidade e considerando a educação das meninas como fundamental para o crescimento econômico responsável.

O objetivo de desenvolvimento sustentável 4 é dedicado à educação e define objetivos que buscam assegurar uma educação inclusiva, equitativa, de qualidade e promover oportunidade de aprendizagem para todos. São objetivos ambiciosos, mas que refletem o quão importante é a educação para todos os âmbitos da sociedade. Segundo Irina Bukova (2017),

é necessária uma mudança fundamental na maneira como pensamos o papel da educação no desenvolvimento global, porque ela tem um efeito catalisador sobre o bem-estar das pessoas e para o futuro do planeta [...]. 
Agora, mais do que nunca, a educação tem a responsabilidade de se alinhar com os desafios e aspirações do século XXI, e promover os tipos certos de valores e habilidades que irão permitir um crescimento sustentável e inclusivo, e uma convivência pacífica. (p. 7)

A iniciativa de investir em uma educação de qualidade para todos como caminho para o desenvolvimento sustentável requer uma mudança de atitude e de olhar sobre os que atuam diretamente nesta área, os professores. Por isso, muitas escolas buscam na certificação do PEA/Unesco uma maneira de receber reconhecimento pelo trabalho realizado. A educação básica é, para as Nações Unidas, o alicerce do desenvolvimento sustentável, a natural demanda das escolas pelos temas do PEA/Unesco e o claro esforço desta organização em atrair mais escolas públicas para a rede de associadas traz esperança e apoio aos professores e comunidade escolar. O foco do programa não é investimento financeiro, mas firmar parcerias entre as escolas associadas para viabilizar a realização dos projetos, além disso, é muito importante a visibilidade dada as escolas associadas, além de formação e oportunidade de troca de experiências com outras escolas buscando incentivar novas formas de ensino:

Uma escola associada da Unesco se caracteriza como um laboratório de ideias, que promove novas abordagens de ensino e aprendizagem baseadas nos valores nos valores e prioridades da Unesco. Apresenta-se, também, como um pólo de formação e aprendizagem colaborativa, permitindo aos diretores das escolas, professores, estudantes e a comunidade escolar integrar os valores da Unesco e se tornar modelos em sua comunidade. (Revista Pea-Unesco, 2017)

O direito a educação de qualidade, a viver em um mundo mais justo em que o valor da cultura, o desenvolvimento sustentável, a paz entre as nações se tornem realidade, requer muito trabalho. As escolas associadas assumem o compromisso de contribuir para que os valores da Unesco sejam disseminados entre as comunidades. A intenção é fazer de cada escola uma célula da organização, que tenha o papel de formar líderes capazes de transformar e melhorar a vida na sua comunidade.

\section{A primeira escola certificada de Santa Maria}

A educação infantil, como primeira etapa da educação básica, tem passado por muitas mudanças desde a Constituição Federal de 1988 e da LDB de 1996, tanto na vinculação à secretaria de Educação, antes era vinculada a Secretaria de Assistência Social, quanto na exigência de formação mínima específica dos professores e na expansão do acesso e na obrigatoriedade dos quatro anos de idade.

Apesar das mudanças em direção à valorização, ainda existe a ideia de que a creche e pré-escola são lugares para deixar a criança enquanto os pais trabalham, visão que os profissionais da Educação Infantil tentam mudar mostrando que o trabalho realizado neste nível de ensino requer uma atenção especial, pois reflete no desempenho das crianças no ensino fundamental.

A escola Municipal de Educação Infantil Borges de Medeiros utiliza os projetos pedagógicos como forma de organização do currículo que considera a realidade das crianças e da comunidade, suas necessidades e interesses na formulação dos projetos 
das turmas. O principal objetivo é criar situações de aprendizagem vinculando as diferentes linguagens ao conhecimento construído pela humanidade, valorizando a cultura local e o conhecimento prévio da criança. Segundo Barbosa e Horn (2008),

um currículo não pode ser a repetição contínua de conteúdos, como uma ladainha que se repete infindavelmente no mesmo ritmo, no mesmo tom, não importando quem ouça, quem observe ou o que se aprende. Afinal, sabe-se que o conhecimento não é verdade imutável, mas algo transitório, inacabado, imperfeito e em contínua pesquisa. Os projetos abrem para a possibilidade de aprender os diferentes conhecimentos construídos na história da humanidade de modo relacional e não-linear, propiciando às crianças aprender através de múltiplas linguagens, ao mesmo tempo em que lhes proporcionam a reconstrução do que já foi aprendido. (Barbosa; Horn, 2008, p. 35)

Partindo desta concepção, o trabalho com projetos possibilita que as necessidades do grupo sejam ouvidas e direcionem o trabalho do professor. As crianças são protagonistas do processo e apresentam para a escola o que a comunidade na qual está inserida tem a colaborar.

O olhar e a escuta do professor e a proposta de trabalho com projetos deu origem a vários trabalhos, como o que foi desenvolvido no ano de 2016: o projeto Com imaginação e ação as crianças transformam em realidade a sustentabilidade. Este projeto que partiu de uma turma de Maternal $2 \mathrm{e}$, originalmente, tinha como objetivo trabalhar a medicina natural pela elaboração de um canteiro de ervas medicinais em um espaço da escola que não era utilizado. Conforme as ações eram desenvolvidas o projeto foi evoluindo para a construção de uma horta e uma composteira, agregando outras aprendizagens. No decorrer da construção da horta o grupo de professores sentiu a necessidade de incluir as outras turmas no processo, com vistas a incentivar o cuidado com aquele espaço, já que todos tinham acesso a ele.

Outros projetos já estavam em andamento envolvendo vários outros temas, como: os valores para a boa convivência, o respeito ao próximo, alimentação saudável, conhecimento de fauna e flora, dos répteis, cuidado com a saúde do corpo, valorização da cultura local com apresentações artísticas e educação musical. Todos estes temas norteavam o trabalho dos professores em 2016 quando se tomou conhecimento do PEA/Unesco.

No projeto principal, Com imaginação e ação as crianças transformam em realidade a sustentabilidade, a turma de Maternal 2 pesquisa sobre as diferentes formas de tratamento natural para doenças, como alternativa aos remédios sintéticos que servem para tratar as doenças, mas que trazem efeitos colaterais muitas vezes mais graves do que as doenças as quais devem tratar. Conhecer alternativas naturais e não agressivas para o corpo, respeitando a natureza e encontrando nela a cura para as doenças foi o foco do trabalho. Esta experiência com as plantas medicinais levou a ampliação dos canteiros e o plantio de hortaliças, já que as crianças demonstraram interesse pelo cultivo de plantas. 
O projeto Eu me remexo muito foi realizado pela turma de Maternal 1 com o objetivo de incentivar as crianças a usarem o corpo de forma saudável. Pensando no fato de que cada vez mais o problema da obesidade avança como uma epidemia entre as crianças por diversos fatores, é necessário criar bons hábitos desde os primeiros anos de vida.

A turma de Pré A desenvolvia o projeto Monstros, que abordava os vírus e bactérias mais conhecidos atualmente e as epidemias causadas por eles, como o vírus H1N1, que causa a Influenza A. Foi feita uma pesquisa a respeito da estrutura dos vírus e bactérias e seus benefícios e malefícios à saúde, além da prevenção e tratamento das principais doenças.

Nas turmas de Pré A e Pré B tarde trabalhava-se o projeto No tempo dos dinossauros, em que as turmas fizeram pesquisas sobre as plantas na época dos dinossauros, passando pela sua evolução até os dias de hoje e sua importância para a manutenção da vida animal.

A turma de Pré B manhã desenvolvia o projeto Conhecendo répteis a partir das cobras, pelo qual se abordava as questões ambientais e de preservação das espécies que, geralmente, são vistas como nocivas. O objetivo era conscientizar as crianças de que as serpentes não são animais nocivos, mas são parte importante na manutenção da biodiversidade do planeta.

Também estava em andamento na turma de Maternal 2 integral 0 projeto Profe, abraço! Construindo atitudes e valores de carinho, amizade e respeito com sujeitos, tempos e espaços na escola de educação infantil. O foco deste projeto foi o convívio das crianças e o estímulo às atitudes de cuidado e respeito com o outro. O projeto objetivava desenvolver a empatia e a capacidade de conviver em harmonia no grupo, evitando conflitos e desenvolvendo a argumentação das crianças na resolução de problemas.

Na turma de Berçário 2, o projeto Que barulhinho bom, o que será que é? tinha como objetivo estimular as áreas cognitiva e social, além de inserir no dia-a-dia das crianças a música e a dança que representam a diversidade cultural do nosso país.

$\mathrm{Na}$ turma de Maternal 1 integral estava em andamento o projeto Meu corpo serve para fazer o bem ao outro, pelo qual se estimulava o uso do corpo e suas possibilidades de movimento dando um significado artístico, pesquisando a cultura do mundo em relação ao corpo e a influencia das diferentes etnias na cultura do nosso país.

A direção da Emei Borges de Medeiros viu nesta proposta uma maneira de valorizar o trabalho dos professores e buscar visibilidade para a escola. Foi apresentado às outras professoras da escola que concordaram em submeter os projetos à avaliação do PEA/Unesco. O projeto relacionado com a horta foi o carro chefe do relatório enviado a Unesco, mas todos os projetos das turmas estavam relatados e organizados conforme os temas e documentados com fotos e descrições. Os documentos foram entregues no prazo, o formulário de adesão e o relatório dos projetos com o cronograma de continuidade para o próximo ano (2017). No dia 9 de fevereiro a escola recebeu a notícia da certificação no PEA/Unesco. 
No entanto, a equipe da escola não parecia ter ideia da dimensão de se tornar uma escola associada e as responsabilidades que teria então. A notícia da certificação foi divulgada na mídia local e trouxe visibilidade para a escola, mas também a responsabilidade de compreender melhor e por em prática os valores da Unesco. Segundo Schultz e losif (2009), que realizaram uma pesquisa em parceria entre Brasil e Canadá sobre o impacto de se tornar uma escola associada Unesco,

o desafio das escolas é fazer com que crianças e jovens aprendam a cultivar o significado da aprendizagem e compreendam sua conexão com os problemas que preocupam e afetam a humanidade. Ensinar a cultivar a comunidade é outro desafio da escola, no sentido de mostrar para o aluno que o mundo lá fora está sempre em transformação e instigando-o para participar do processo de construção de comunidades mais justas e humanas. Cultivar responsabilidade pela promoção da justiça social seria o terceiro desafio da escola, contribuindo para a formação de cidadãos com a habilidade de responder ativamente diante de situações de injustiça social e de assumirem posição de liderança na luta por um mundo melhor. Para dar conta de assumir tal desafio, a escola precisa adotar uma postura ética e todos seus membros devem assumir uma postura de liderança diante da promoção da justiça social. (p. 4)

Ser uma escola associada requer um trabalho intenso em busca da disseminação dos valores da Unesco, não só no trabalho com as crianças, nos projetos realizados, na divulgação das datas comemorativas da organização, mas também no que se estende a comunidade. O bairro no qual a escola está inserida deve ser foco das ações da comunidade escolar, pequenas ações realizadas de conscientização, que levam para fora da escola os ideais da Unesco e que atraiam para dentro da escola pais e comunidade num clima de colaboração e aprendizagens mútuas, é um dos desafios propostos aqueles que se tornam integrantes das escolas associadas.

O desafio de tornar a escola um espaço aberto de aprendizagens e trocas entre a comunidade requer um olhar sensível para realidade das famílias das crianças, valorização da cultura, da história de vida, seus sonhos e perspectivas. À escola cabe a tarefa de ouvir e buscar alternativas para uma comunidade mais sustentável em que todos com suas habilidades possam contribuir para a melhoria da qualidade de vida de todos.

A relação família-escola é, por vezes, difícil de mediar, em muitos casos a escola não permite que pais interfiram ou se manifestem de alguma forma em relação às normas e organização, por outro lado, há pais que não querem ter nenhum tipo de preocupação ou envolvimento com o que acontece na escola de seus filhos, deixando de acompanhar ou de participar dos eventos da escola ou das reuniões de pais. Trazer as famílias para a escola é um desafio na atualidade, pois cada vez mais as famílias estão se distanciando desse espaço. O caminho para mudar esta realidade pode estar no esforço dos professores e direção da escola em entender o contexto das famílias das crianças e se aproximar destas sem cobranças ou acusações. A escola deve ter a iniciativa de incluir as famílias neste espaço, de trazê-las e acolhe-las, Iniciando o processo de abertura para provocar mudanças efetivas. 
Na Emei Borges de Medeiros procura-se promover a participação das famílias por meio de pequenas ações de conscientização a respeito do cuidado com o meio ambiente e da utilização do espaço da horta da escola como um lugar de integração entre as famílias. A ideia é trazer as famílias para a escola incentivando-as a ajudar nos cuidados com a horta que ao longo do ano trazem produtos para a própria comunidade. Nos eventos realizados, em que as família são convidadas a participar, como na Festa da família, são propostas atividades de intervenção no espaço escolar. As famílias podem ajudar no embelezamento da escola, na limpeza da horta e no plantio de mudas.

Outra preocupação da Unesco se refere a formação dos professores. Compreender os objetivos da instituição, atualizar-se no uso das novas tecnologias de comunicação que possibilitem a troca de informações tanto de professores quanto de crianças com outras escolas associadas é outro desafio a ser enfrentado. Os professores devem estar preparados para formar pessoas com engajamento e liderança, conscientes de seu papel na sociedade. Por isso, na Emei Borges de Medeiros as formações dos professores são voltadas para as necessidades do grupo e todos os anos a formação continuada no espaço da escola possibilita discussões e reflexões a respeito de temas atuais e que servem para qualificar o trabalho e superar antigas formas de abordagem.

Os temas da Unesco são demanda das formações, pois refletem problemas atuais que vão da perspectiva mundial para a local. Os quatro temas que envolvem desenvolvimento sustentável, educação para a paz, os problemas mundiais e o papel das Nações Unidas e a aprendizagem intercultural são parte do trabalho realizado na comunidade em que a escola atua. Por isso abordar os temas da Unesco na formação continuada dos professores na escola, ter conhecimento dos documentos, propostas e relatórios é fundamental para qualificar o trabalho na educação infantil.

\section{Considerações finais}

As mudanças nas políticas públicas para a educação infantil, a busca por uma educação básica de qualidade, mais investimento na infra-estrutura das escolas e formação de professores mostram o quanto a sociedade e os movimentos sociais tem lutado por seus direitos. Mesmo que a qualidade da educação envolva vários fatores, um dos aspectos mais importantes é a formação dos professores e sua valorização.

O Programa Escolas Associadas da Unesco é uma ótima oportunidade de dar visibilidade as escolas de educação infantil, seguindo a experiência da Emei Borges de Medeiros, outras escolas de educação infantil também têm a oportunidade de mostrar seu trabalho, seus projetos e valorizar o que o professor faz na escola. Diferente de outros programas desenvolvidos, o PEA-Unesco destaca o conjunto de ações desenvolvidas na escola, além de difundir os ideais da Unesco.

No entanto, se tornar uma escola associada da Unesco significa assumir responsabilidades de difundir os ideais desta instituição, requer formação constante dos professores e um estudo aprofundado dos documentos e relatórios da Unesco, além do compromisso de estender os valores desta instituição a comunidade em que a escola atua.

Traçar metas e estratégias para as próximas ações na escola requer um movimento entre escola e comunidade, planejar as ações em conjunto e dar sentido ao trabalho da escola que vá além da instrução, mas que a escola realmente assuma seu caráter 
educacional em parceria com as famílias. Participar do Programa Escolas Associadas da Unesco é um movimento para a escola que desacomoda as pessoas e leva a uma união dos professores e comunidade escolar em busca do bem comum. Os desafios são muitos: investir na formação dos professores, unir as propostas da Unesco a realidade da escola, superar as dificuldades e unir escola e comunidade são as principais metas para a Emei Borges de Medeiros, a primeira escola PEA/Unesco de Santa Maria.

\section{Referências}

BARBOSA, Maria Carmem Silveira; HORN, Maria da Graça. Projetos pedagógicos na educação infantil. Porto Alegre: Artmed, 2008.

BRASIL. Constituição da República Federativa do Brasil. Brasília: Senado, 1988.

BRASIL. Lei n. 9.394, de 20 de dezembro de 1996. Estabelece as diretrizes e bases da educação nacional. Brasília: Congresso Nacional, 1996.

CAMPOS, Maria Malta; ROSEMBERG, Fulvia; FERREIRA, Isabel M. Creches e préescolas no Brasil. São Paulo: Cortez, 1993.

INSUMOS PARA O DEBATE 2. Emenda constitucional n. 59/2009 e a educação infantil: impactos e perspectivas. São Paulo: Campanha Nacional pelo Direito à Educação, 2010.

KUHLMANN JÚNIOR, Moisés. O jardim de infância e a educação das crianças pobres: final do século XIX início do século XX. In: MONARCHA, Carlos. Educação da infância brasileira 1875-1983. São Paulo: Autores Associados, 2001, p. 50-72.

REVISTA PEA-UNESCO. Brasília: Unesco, ano 9, n. 11, 2017.

UNESCO. Educação para os objetivos de desenvolvimento sustentável: objetivos de aprendizagem. Brasília: Unesco, 2017.

UNESCO. Os serviços para a criança de 0 a 6 anos no Brasil. Brasília: Unesco, 2003. Disponível em <https://nacoesunidas.org/agencia/unesco>. Acesso em 22 out. 2016.

UNESCO. Relatório de monitoramento global 2016: educação para as pessoas e o planeta: criar futuros sustentáveis para todos. UNESCO PARIS, 2016. Disponível em unesdoc.unesco.org/images/0024/002457/245745POR.pdf. Acesso em 22 out. 2016.

CASTRO, Jane Margareth; REGATTIERI, Marilza. Interação escola-família: subsídios para práticas escolares. Brasília: Ministério da Educação, 2010.

SHULTZ, Lynette; IOSIF, Ranilce Guimarães. O impacto de se tornar uma escola associada da UNESCO (PEA) no Brasil. Edmonton: University of Alberta, 2009. Disponível em <https://nacoesunidas.org/agencia/unesco>. Acesso em 22 out. 2016.

Gilsilene Rony Pereira Alves é licenciada em Pedagogia pela Universidade Federal de Santa Maria e professora na Escola Municipal de Educação Infantil Borges de Medeiros, em Santa Maria/RS.

Endereço: Rua Tuiuti, 1840/504 - 97015-662 - Santa Maria - RS - Brasil.

E-mail: grpalves@yahoo.com.br. 
Sabrina Magrini Peixoto Machado é licenciada em Pedagogia pela Universidade Federal de Santa Maria e professora na Escola Municipal de Educação Infantil Borges de Medeiros, em Santa Maria/RS.

Endereço: Rua Rádio Guarathan, 1800 - 97030-118 - Santa Maria - RS - Brasil.

E-mail: sabrina peixoto@msn.com.

Recebido em 11 de outubro de 2017.

Aceito em 3 de dezembro de 2017. 